\title{
CRENÇAS DE ESTUDANTES E PROFESSORES DE LICENCIATURA EM LETRAS SOBRE O ENSINO-APRENDIZAGEM DE LÍNGUAS
}

\author{
Mellissa Moreira Figueiredo Barbosa ${ }^{1}$; Milenna Brun²; \\ 1. Bolsista PEVIC/UEFS, Graduando em Letras com inglês, Universidade Estadual de Feira de Santana, e-mail: \\ mellissabarbosa@hotmail.com.br \\ 2. Orientadora, Departamento de Letras e Artes, Universidade Estadual de Feira de Santana, e-mail: \\ $\underline{\text { milennab@uefs.br }}$
}

PALAVRAS-CHAVE: crenças; ensino-aprendizagem de línguas; BALLI.

\section{INTRODUÇÃO}

O estudo sobre crenças vem crescendo no mundo desde os anos 70 (Honselfeld, 1978), mostrando assim ter uma importância significativa para o processo de ensinoaprendizagem de uma língua estrangeira (doravante LE). Hoje, um estudo deste tipo ainda se faz extremamente relevante no contexto educacional, pois com a identificação e investigação das crenças dos estudantes e professores pode-se promover uma tomada de consciência e o desenvolvimento de um processo crítico-reflexivo diante daquilo que os envolvidos naquele contexto acreditam. Cada aprendiz tem uma crença sobre quais são os melhores métodos e estratégias para sua aprendizagem, por exemplo. O conhecimento sobre essas especificações pode contribuir para que o processo de ensinoaprendizagem de uma LE seja mais bem-sucedido, através da desconstrução ou do reforço das crenças dos alunos e professores.

Nas palavras de Barcelos (2006), crenças são definidas como:

uma forma de pensamento, como construções da realidade, maneiras de ver e perceber o mundo e seus fenômenos, co-construídas em nossas experiências e resultantes de um processo interativo de interpretação e (re)significação. Como tal, crenças são sociais (mas também individuais), dinâmicas, contextuais e paradoxais. (Barcelos, 2006, p.18)

Nesse contexto, observa-se que essa co-construção em nossas experiências afetam a forma como se aborda o processo de ensino-aprendizagem de línguas, tanto para professores quanto para aprendizes, e consequentemente, a forma como o conceito de língua é concebido e como o conhecimento é mediado em sala de aula. O professor tem grande responsabilidade nesse processo, pois sendo sujeito transformador da realidade em sala de aula, tem um papel fundamental na construção do sistema de crenças dos estudantes.

Visto que professores e aprendizes podem apresentar crenças diferentes, é possível haver conflitos entre o que eles pensam sobre o processo de ensinoaprendizagem de LE e/ou haver uma reprodução das crenças dos professores pelos estudantes.

\section{MATERIAL E MÉTODOS OU METODOLOGIA (ou equivalente)}


De acordo com Barcelos (2001), a abordagem normativa tem caráter descritivo e classificativo com relação às crenças sobre o ensino-aprendizagem de línguas $\mathrm{O}$ uso de escalas como a Likert-scale é bastante comum neste tipo de investigação $\mathrm{O}$ inventário Beliefs About Language Learning Inventory (BALLI) (Horwitz, 1987) é um dos mais usados atualmente, apesar de ter recebido muitas críticas, ao atestar, através de afirmações pré-estabelecidas, quais crenças os participantes do estudo possuem.

Nesse contexto, ao desenvolver esse plano de trabalho, houve um período contínuo de formação teórica sobre crenças do ensino-aprendizagem de línguas estrangeiras através de discussões e debates. Em seguida os dados foram coletados através do questionário BALLI (Horwitz, 1987) com os estudantes e professores do primeiro semestre do curso de Licenciatura em Letras com Inglês, Francês, Espanhol e Vernáculas da Universidade Estadual de Feira de Santana a fim de investigar as crenças desses aprendizes acerca da dificuldade na aprendizagem de línguas; da natureza da aprendizagem de línguas; das estratégias de aprendizagem e comunicação, da motivação e das expectativas. Quanto ao processo de análise de dados, estes não chegaram a ser analisados estatisticamente após a aplicação, comparação e interpretação.

\section{RESULTADOS E/OU DISCUSSÃO (ou Análise e discussão dos resultados)}

Os sujeitos participantes ao responder o questionário da pesquisa revelaram suas crenças ao passo que também deixaram claro como os estudantes de cada curso se assemelham e se diferenciam dentro do que acreditam.

Nesse contexto, contribuímos com os estudos sobre crenças de alunos e professores acerca do processo de ensino-aprendizagem de línguas estrangeiras quando discutimos a pesquisa e textos sobre esse tópico nos encontros do grupo de pesquisa ELCE. A bolsista envolvida no projeto desenvolveu seu trabalho de conclusão de curso sobre esse mesmo tema e teve a oportunidade de discutir e divulgar esse tema com a comunidade acadêmica, assim apoiando a formação da bolsista e contribuímos para as ações de pesquisa na UEFS.

Reconhecemos as crenças apresentadas sobre o processo de ensinoaprendizagem de línguas ao aplicar o questionário BALLI com os estudantes e professores de Letras dessa instituição. Ao responder o questionário os estudantes e professores passaram por um processo reflexivo sobre o ensino-aprendizagem de línguas, e tiveram a oportunidade de desenvolver uma consciência maior sobre como suas crenças podem interferir na formação de sujeitos aprendentes e ensinantes.

Não alcançamos nenhum resultado quantitativo até o momento, pois ainda não conseguimos processar os dados no programa SPSS. Os dados da pesquisa só serão revelados uma vez que processados e analisados no programa.

\section{CONSIDERAÇÕES FINAIS (ou Conclusão)}

Nessa pesquisa, identificamos as crenças de estudantes e professores dos cursos de Letras acerca do processo de ensino-aprendizagem de línguas a partir da aplicação dp questionário BALLI. Não obtivemos resultados palpáveis, pois enfrentamos dificuldades durante a pesquisa para encontrar um especialista em estatística para processar os dados no devido software. 
Em relação aos participantes, responder o questionário BALLI contribuiu para o desenvolvimento crítico-reflexivo desses professores em formação e no auxílio aos docentes universitários atuantes em relação à reflexão e à ressignificação de muitas de suas crenças.

\section{REFERÊNCIAS}

BARCELOS, A.M.F. Metodologia de pesquisa das crenças sobre aprendizagem de línguas: estado da arte. Revista Brasileira de Linguística Aplicada, v.1, n.1, p.71-92, 2001.

Cognição de professores e alunos: Tendências recentes na pesquisa de crenças sobre ensino e aprendizagem de línguas. In: BARCELOS, A.M.F.; VIEIRAABRAHÃO, M.H. (Org.) Crenças e Ensino de Línguas: foco no professor, no aluno e na formação de professores. Campinas, SP: Pontes, 2006. p.15-42.

HORWITZ, E. K., Surveying student beliefs about language learning. In A. Wenden \& J. Rubin (Eds.). Learner strategies in language learning. Englewood Cliffs, NJ: PrenticeHall (p.119-129), 1987.

HOSENFELD, C. Students' mini theories of second language learning. Association Bulletin, v.29, n.2, 1978. 